Article

\title{
Spatio-Temporal Variability of Winter Monsoon over the Indochina Peninsula
}

\author{
Sirapong Sooktawee ${ }^{1}$, Usa Humphries ${ }^{2, *}$, Atsamon Limsakul ${ }^{3}$ and Prungchan Wongwises ${ }^{1}$ \\ 1 The Joint Graduate School of Energy and Environment, Center for Energy Technology and \\ Environment, King Mongkut's University of Technology Thonburi, 126 Prachauthit Road, \\ Bangmod, Tungkru, Bangkok 10140, Thailand; E-Mails: sirapong@deqp.go.th (S.S.); \\ prungchan.won@kmutt.ac.th (P.W.) \\ 2 Department of Mathematics, King Mongkut's University of Technology Thonburi, 126 Prachauthit \\ Road, Bangmod, Tungkru, Bangkok 10140, Thailand \\ 3 Environmental Research and Training Center, Department of Environmental Quality Promotion, \\ Klong 5, Klong Luang, Pathum Thani 12120, Thailand; E-Mail: atsamon@deqp.go.th \\ * Author to whom correspondence should be addressed; E-Mail: usa.wan@kmutt.ac.th; \\ Tel.: +66-247-081-32.
}

Received: 29 December 2013; in revised form: 10 February 2014 / Accepted: 17 February 2014 / Published: 20 February 2014

\begin{abstract}
In this study, the spatial patterns and their interannual variability of wintertime low-level winds over the Indochina Peninsula (IDP) were studied by using the analysis of the empirical orthogonal function for complex numbers. The leading mode accounts for $46.6 \%$ of the total variance. The composite and regressed patterns of wind components show dominant northeasterly wind over the IDP, which are related to the East Asia winter monsoon (EAWM) circulation and connected to the cyclonic circulation near Borneo. The correlations between the EAWM indices and the leading principal component (PC) suggest the plausible connections between the low-level wind over the IDP and EAWM predominantly via the wind circulation. We also performed correlation analysis on the relationship between leading mode and sea surface temperature anomalies (SSTAs). The result indicates that there is a linkage between the northeasterly wind over the IDP and EAWM and with SSTAs in the Pacific Ocean. This study provides useful information and a mechanism related to the monsoon variability over the IDP.
\end{abstract}


Keywords: Indochina; winter monsoon; variability; sea surface temperature

\section{Introduction}

The Indochina Peninsula (IDP) is a geographically unique entity situated between the Indian subcontinent and East Asia, where two contrasting Asian monsoon systems exhibit distinct characteristics [1-3]. During the boreal winter, the climate condition over the IDP is dominated by the meridional circulation associated with the intensified Siberian high (SH) [4]. It is generally characterized by ascending warm air over the Indonesian maritime continent and descending cold continent air over China, resulting in two major branches of low-level wind fields blowing toward the subtropical western Pacific and South China Sea [5]. A succession of northeasterly surges with outbursts of SH is one of the most conspicuous features of the East Asian winter monsoon (EAWM) [6]. The active EAWM exerts a strong impact on the extratropical and tropical planetary-scale circulations and influences the convection over the tropical western Pacific [6], and its variability is linked to the forcing from sea surface temperature anomalies in the tropical Pacific Ocean $[3,6,7]$. Although the Pacific Ocean is absolutely crucial, the Indian Ocean is also important for the Asian monsoon variability [8]. Available evidence has indicated that the variability of EAWM exerts social-economic impacts on many Asian countries [4-6]. Hence, a better understanding of EAWM variability is still a great scientific challenge and concern.

The variability of EAWM and its strength can be characterized by wind behavior at many levels [5,6,9-11]. These winds have been used to construct the indices, such as wind at $10 \mathrm{~m} \mathrm{[5]}$ and wind at $1,000 \mathrm{hPa}[6,10]$. Many indices derived from low-level wind have been introduced to reveal the intensity of the EAWM [12]. In general, $850 \mathrm{hPa}$ wind circulation is less influenced by surface roughness than the wind at the $10 \mathrm{~m}$ and 1,000 hPa levels. Furthermore, upper-level wind, sea level pressure (SLP) and trough behavior can be used to characterize the monsoon strength as an index representing different aspects of the EAWM [12]. For example, the index derived from zonal wind at the $300 \mathrm{hPa}$ level represents the association between the East Asian jet stream and EAWM variation [12]. To further extend our current understanding, the relationship between EAWM indices and winter monsoon over the IDP is of great interest, because the IDP is a tropical regional scale that has different climate features from the larger scale. Furthermore, this is also due to the fact that the winter monsoon variability over the IDP has less studies than its summer counterpart [2,11,13-16]. These are importance for the IDP countries and their neighbors.

It is widely accepted that sea surface temperature (SST) variability in the equatorial Pacific Ocean plays an important role in atmospheric processes and climate variability. Many previous studies have shown that SST variability associated with El Niño-Southern Oscillation (ENSO) events strongly affects the EAWM [7,17-20], and the SST in the Indian Ocean is important [8]. Thus, there is a possibility to have some roles of the SST variability playing on the winter monsoon over the IDP.

In this study, we analyzed the monthly gridded data using an analysis of the empirical orthogonal function for complex numbers to reveal spatio-temporal structures of wintertime winds over the IDP and to disclose any possible connections to the EAWM. The relationships between the SST and wintertime 
low-level wind, representing winter monsoon, and its impact on precipitation are further illustrated. These analyses aim at providing empirical evidence in support of a better understanding of winter monsoon over the IDP, demonstrating some connections to the EAWM and its association with SST variation.

\section{Data and Analytical Methods}

The monthly gridded data of the Japanese 25 -year reanalysis dataset (JRA-25) with $1.25^{\circ} \times 1.25^{\circ}$ horizontal resolution [21] during the boreal winter months (December-January-February) covering the period of 1979-2010 were used for this study. The wind data at $850 \mathrm{hPa}$ were extracted for the IDP region $\left(5^{\circ}-30^{\circ} \mathrm{N}, 90^{\circ}-110^{\circ} \mathrm{E}\right)$ to analyze the dominant spatio-temporal modes by the empirical orthogonal function (EOF) method. Because winds have magnitude and direction, the vector analysis is more suitable than the traditional scalar analysis to keep the meaning of the wind. Some previous studies used EOF to analyze wind components by forming the complex numbers [22-24]. The wind vector is in complex exponential form and is defined by the direction measuring from East to North and the magnitude of the vector as the wind speed [22]. Furthermore, the wind vector in complex rectangular form consists of the zonal and meridional wind components, represented by the real and imaginary parts, respectively, and can be used for the analysis, as well [23]. In this study, the wind components at $850 \mathrm{hPa}$ were used to form a complex number in a rectangular form with respect to the zonal and meridional axes. A matrix ( $\mathbf{S})$ of dimension $N \times M$ consists of complex number elements $\left(e_{k m}\right)$ formed as follows:

$$
e_{k m}=u_{k m}^{\prime}+i v_{k m}^{\prime}
$$

where $u^{\prime}, v^{\prime}, k=1, \ldots, N$, and $m=1, \ldots, M$ denote for zonal wind anomaly, meridional wind anomaly, the location and time of the data, respectively. To analyze a matrix of complex number elements by EOF, a symmetric composition of complex numbers, except for diagonal elements, named the Hermitian matrix ( $\mathbf{H})$, is required. There are important properties of $\mathbf{H}$, which are as follows: (1) eigenvalues are real; (2) eigenvectors corresponding to the distinct eigenvalues meet orthogonally; and (3) it is unitarily diagonalizable. The matrix used to form a Hermitian matrix for the analysis presents as:

$$
\mathbf{H}=M^{-1} \mathbf{S S}^{\dagger}
$$

where $\mathbf{H}$ is the Hermitian matrix and $\mathbf{S}^{\dagger}$ is the complex conjugate transpose of the sample matrix ( $\mathbf{S}$ ) that has $M$ time series records. Therefore, eigenvectors $\left(\hat{\mathbf{E}}_{j}\right)$ are determined by:

$$
\mathbf{H} \hat{\mathbf{E}}_{j}=\lambda_{j} \mathbf{E}_{j}, \quad j=1, \ldots, N
$$

and satisfy the unitary condition:

$$
\hat{\mathbf{E}}_{i}^{\dagger} \mathbf{E}_{j}=\delta_{i j}
$$

where $\hat{\mathbf{E}}_{i}^{\dagger}$ is the complex conjugate transpose of $\hat{\mathbf{E}}_{i}$ and $\delta_{i j}$ is the Kronecker delta function. Thus, the eigenvalues,$\lambda_{j}$, are real, and the complete set of $N$ eigenvectors meets the orthogonality condition. The eigenvectors, $\hat{\mathbf{E}}_{j}$, are called modes of empirical orthogonal analysis. They are used to expand data as:

$$
\mathbf{S}_{m}=\sum_{k=1}^{N} c_{k m} \hat{\mathbf{E}}_{k}, \quad m=1, \ldots, M
$$

where

$$
c_{k m}=\hat{\mathbf{E}}_{k} \mathbf{S}_{m}, \quad k=1, \ldots, N ; m=1, \ldots, M
$$


The $c_{k m}$ is unique and in complex number form (hereafter referred to as the principal component (PC)). Nevertheless, there is an arbitrary phase factor $\left(\theta_{k}\right)$ associated with the $k$-th eigenvector; the set of vectors is $\exp \left(i \theta_{k}\right) \hat{\mathbf{E}}_{k}$. We take this into account by choosing $\theta_{k}$ when the mean value of the argument is nearly zero to orient the corresponding eigenvector and PC [22]. Thus, the real component variation represents variation in magnitudes of corresponding eigenvector elements, whereas the imaginary part that is perpendicular to the vector indicates the strength of the vector rotation in a counterclockwise direction [23]. The EOF analysis for complex numbers dealing with two components, which is suitable to present co-varying spatial patterns [25], was performed. It differs from the EOF analysis for complex numbers dealing with one variable to capture propagating patterns and differs from the complex Hilbert EOF analysis (sometimes, it is referred to as the complex EOF analysis) related to the frequency domain [25].

Since the EAWM is the prominent climate feature during the winter season, it is important to reveal the relationship between the winter monsoon over the IDP and the EAWM. The leading PC of the wintertime low-level winds over the IDP given by EOF analysis of complex numbers was then used to present the variability of the winter monsoon over the IDP. Any relationships of them were explored based on correlation analysis between the leading PC and the EAWM indices derived from wind fields and SLP. Eight EAWM indices were calculated based on the JRA-25 data for the boreal winter period (Table 1). The regression technique [26] was utilized to separate the signal into two parts, which are the low-level wind variability over the IDP related to the feature of interest and the unrelated part.

Finally, the SST data obtained from the Hadley Centre sea ice and sea surface temperature dataset (HadISST) with $1^{\circ} \times 1^{\circ}$ resolution [27] and the monthly gridded data of precipitation from the University of Delaware (UDel) with $0.5^{\circ} \times 0.5^{\circ}$ horizontal resolution [28] from the National Oceanic and Atmospheric Administration/Office of Oceanic and Atmospheric Research/Earth System Research Laboratory (NOAA/OAR/ESRL) were used for analyses of its relation to SST variability and its impacts on precipitation, respectively.

Table 1. The selected East Asia winter monsoon (EAWM) indices for the correlation analysis. SLP, sea level pressure.

\begin{tabular}{|c|c|c|c|}
\hline No. & Index & Index Representative & Reference \\
\hline 1 & $I_{\text {Chen }}$ & $\begin{array}{l}\text { An average of the meridional wind component at } 10 \mathrm{~m} \text { over the region of the East China } \\
\text { Sea }\left(25^{\circ}-40^{\circ} \mathrm{N}, 120^{\circ}-140^{\circ} \mathrm{E}\right) \text { and the South China Sea }\left(10^{\circ}-25^{\circ} \mathrm{N}, 110^{\circ}-130^{\circ} \mathrm{E}\right) \text {. }\end{array}$ & {$[5]$} \\
\hline 2 & $I_{\text {Liu-M }}$ & $\begin{array}{l}\text { An average of the meridional wind component at the } 1,000 \mathrm{hPa} \text { level over the mid-high } \\
\text { latitude area }\left(30^{\circ}-50^{\circ} \mathrm{N}, 110^{\circ}-125^{\circ} \mathrm{E}\right)\end{array}$ & {$[10]$} \\
\hline 3 & $I_{\text {Liu-L }}$ & $\begin{array}{l}\text { An average of the meridional wind component at the } 1,000 \mathrm{hPa} \text { level over the } \\
\qquad \text { low-latitude area }\left(10^{\circ}-25^{\circ} \mathrm{N}, 105^{\circ}-135^{\circ} \mathrm{E}\right) .\end{array}$ & {$[10]$} \\
\hline 4 & $I_{\mathrm{Ji}}$ & $\begin{array}{l}\text { An average of the meridional wind component at the } 1,000 \mathrm{hPa} \text { level over the area of } \\
\qquad 10^{\circ}-30^{\circ} \mathrm{N}, 115^{\circ}-130^{\circ} \mathrm{E} .\end{array}$ & {$[6]$} \\
\hline 5 & $I_{\mathrm{Lu}}$ & $\begin{array}{l}\text { An average of the meridional wind component at the } 1,000 \mathrm{hPa} \text { level over the South } \\
\qquad \text { China Sea }\left(7.5^{\circ}-20^{\circ} \mathrm{N}, 107.5^{\circ}-120^{\circ} \mathrm{E}\right) .\end{array}$ & [9] \\
\hline 6 & $I_{\mathrm{Xu}}$ & A sum of the zonal SLP differences $\left(110^{\circ} \mathrm{E}\right.$ minus $\left.160^{\circ} \mathrm{E}\right)$ from $20^{\circ} \mathrm{N}$ to $50^{\circ} \mathrm{N}$. & {$[29]$} \\
\hline 7 & $I_{\mathrm{Wu}}$ & A sum of the zonal SLP differences $\left(110^{\circ} \mathrm{E}\right.$ minus $\left.160^{\circ} \mathrm{E}\right)$ from $20^{\circ} \mathrm{N}$ to $70^{\circ} \mathrm{N}$. & {$[30]$} \\
\hline 8 & $I_{\text {Jhun }}$ & $\begin{array}{l}\text { A difference in the area-averaged zonal wind speed at the } 300 \mathrm{hPa} \text { level between a } \\
\text { region of } 27.58^{\circ}-37.58^{\circ} \mathrm{N}, 110^{\circ}-170^{\circ} \mathrm{E} \text { and a region of } 50^{\circ}-60^{\circ} \mathrm{N}, 80^{\circ}-140^{\circ} \mathrm{E} \text {. }\end{array}$ & [31] \\
\hline
\end{tabular}




\section{Wintertime Low-Level Wind over the IDP}

This section aims at presenting and discussing the spatio-temporal variability of wintertime low-level wind over the IDP and exploring any relations to EAWM.

\subsection{Spatio-Temporal Variability of Wintertime Low-Level Wind}

According to a branch of EAWM that can penetrate into the tropical region [5] and that can influence the wind over the IDP region, we present the possible connection of the wind over the IDP to the EAWM. First of all, the climatic low-level wind pattern over the IDP presents the dominant winds blowing from the east to the west, and they split into two branches that turn northward and move forward around $15^{\circ} \mathrm{N}$ (Figure 1a). The result of EOF analysis shows the first mode of wintertime low-level wind anomalies over the IDP accounting for $46.6 \%$ of the total variance. The spatial pattern shown in Figure $1 \mathrm{~b}$ is quite similar to the climatic pattern, because it contributes most of the variance. The corresponding PC time series, which consists of real and imaginary parts (hereafter referred to as primary and secondary components (PCpri and PCsec, respectively)) are shown in Figure 1c. The time series of the PC1pri and PC1sec exhibit large interannual variations, and they significantly correlate with each other.

Figure 1. Spatial patterns of (a) the climatic wintertime wind at $850 \mathrm{hPa}$ (unit is $\mathrm{m} \cdot \mathrm{s}^{-1}$ ) and (b) the leading mode and (c) the corresponding time series, PC1 (principal component 1). Note that shading represents topography (units are meters).
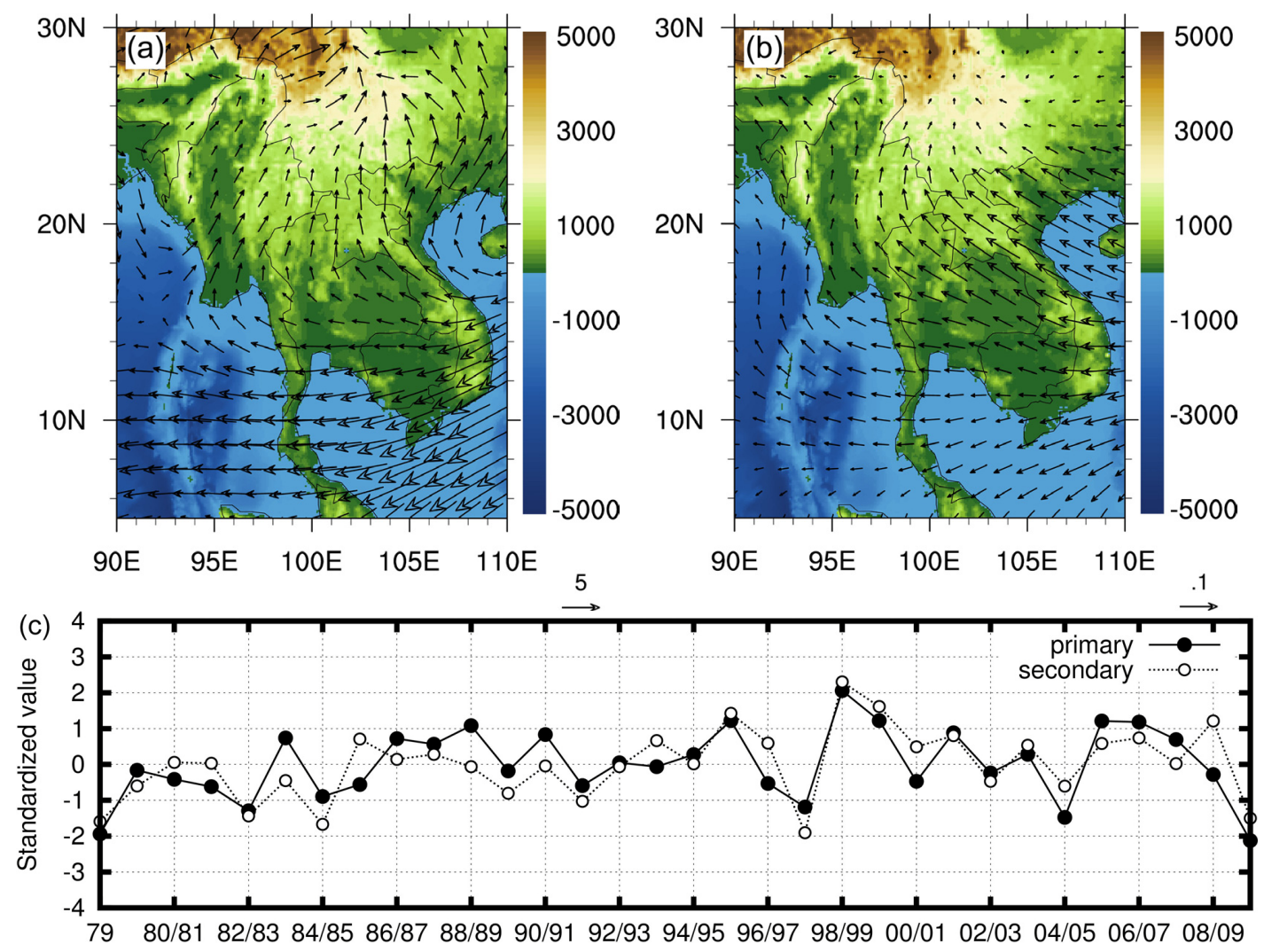

The correlation coefficient between PC1pri and PC1sec is 0.75 with a 0.01 significance level. It indicates that the signal variations of them are in-phase, meaning that variations of two wind 
components are in-phase to each other. Their being in phase suggests the change of the wind vector amplitude in the counterclockwise direction, which is perpendicular to the vectors given by the leading mode related to the change of amplitude in the parallel direction. Thus, the spatial wind patterns were further constructed by regressions of zonal and meridional wind anomalies on PC1pri and PC1sec (PC1s). Both patterns show a strong in-phase pattern of wind, which is a northeasterly wind over the IDP and the South China Sea (SCS) (Figure 2a,b), which agrees with the in-phase variations of PC1s. The increases in the positive direction of both PC1s indicate the enhancement of the northeasterly wind over the IDP, and vice versa for the negative direction. This analysis provides additional evidence supporting the variations of PC1s related significantly to the change of northeasterly wind over the IDP and the SCS.

The variations of PC1s were categorized into strong and weak phases when the PC values are greater and less than 1SD and-1SD, respectively. The composite spatial patterns of anomalous wind and sea level pressure (SLP) for the strong and weak phases are shown in Figure $2 \mathrm{c}-\mathrm{f}$, which indicate strengthening northeasterly wind during the strong phase of PC1s and weakening northeasterly wind during the weak phase.

Figure 2. Regression maps of winter (DJF) $850 \mathrm{hPa}$ wind components on (a) the primary component (PC1pri) and (b) the secondary component (PC1sec) of PC1 (units are in meters per second, and shading represents the 0.05 significance level correlated area to the meridional wind), whereas (c) and (d) are composite circulations for the strong phases of PC1pri and PC1sec (greater than 1SD) and (e) and (f) are patterns for the weak phases of PC1pri and PC1sec (less than-1SD), respectively. The contour line and shading in (c) to (f) represent composite anomalous SLP and the 0.05 significance level, respectively.
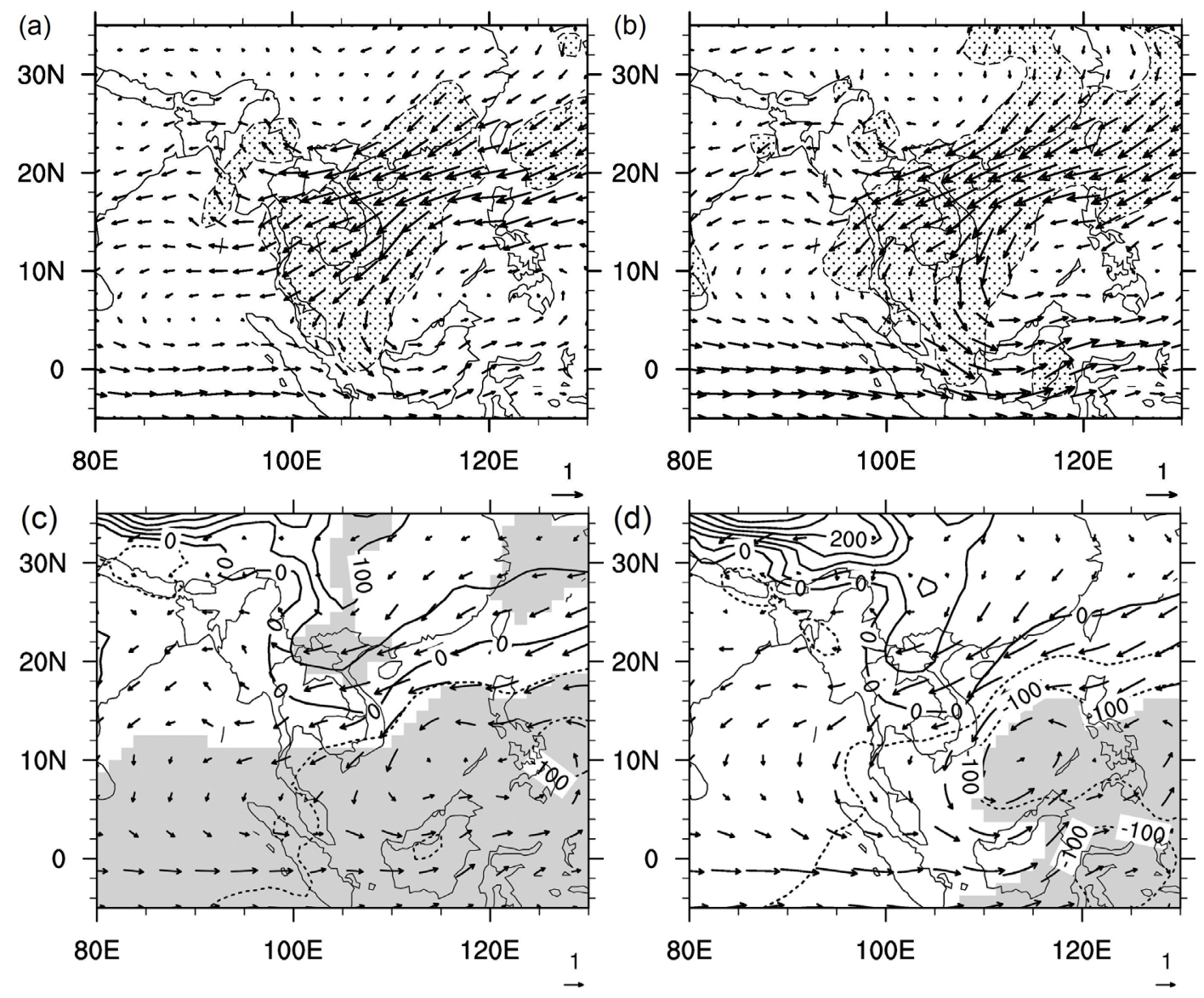
Figure 2. Cont.
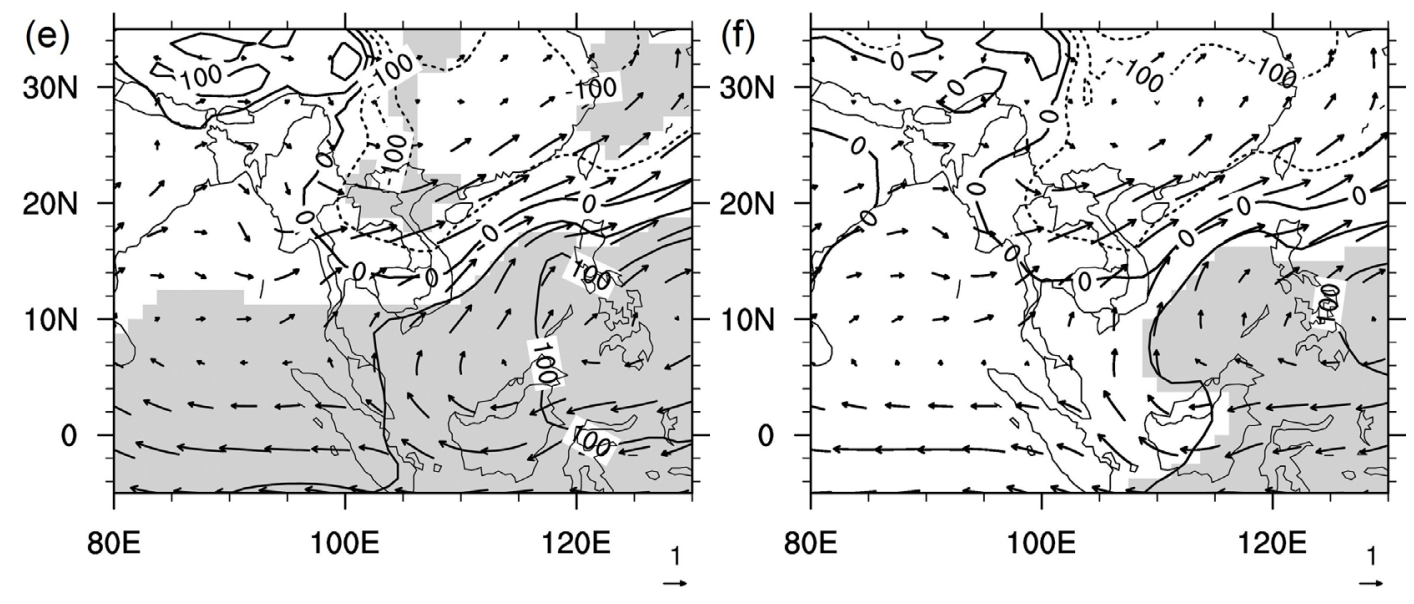

During the strong (weak) events, there is an increasing (decreasing) of anomalous SLP over the mainland and a decreasing (increasing) of anomalous SLP over the maritime continent and the SCS (Figure 2c,d). The patterns show the contrast of anomalous SLP between the mainland over higher latitude areas and the ocean, which indicates the thermal contrast between both areas. This is a reason for the changing of the northeasterly wind strength over the IDP. The patterns also represent northeasterly wind over the IDP, and the winds blow quite parallel to the isobars that resulted from the pressure gradient, the Coriolis force and centrifugal forces, whereas the Coriolis force becomes zero at the Equator. It is also evident that the variations in the northeasterly wind are linked to the cyclonic circulation, related to the centrifugal force, near Borneo. The cyclonic circulation presents the anomalous low pressure over the maritime continent (Figure 2c,d). For the PC1sec, it presents the larger anomalous low pressure near Borneo than that of the PC1pri. This implies the change of wind amplitude in the counterclockwise direction, which is perpendicular to the vectors given by the first EOF, which is more associated with the larger anomalous low pressure and cyclonic circulation than the change of wind amplitude in the parallel direction. These results agree with a previous study [5], indicating that an anomalous cyclonic circulation appears around the Philippines during the strong phase of EAWM, and other studies [32,33], showing that northeasterly wind may interact with a synoptic scale feature, known as the Borneo vortex, located over northern Borneo.

The northeasterly wind governs over the IDP, which is the small regional wind compared to the area governed by the EAWM that covers East Asia and neighboring regions. It is important to present the large-scale circulation and factors that related to the variability of the northeasterly wind over the IDP. During the winter season in East Asia, the pressure over Siberia and northern China becomes higher (lower) in strong (weaker) EAWM phases [5], which is quite similar to the patterns of the composite SLP difference given by PC1s, as shown in Figure 3.

There is strong positive anomalous SLP over the areas around the Siberian high and the Aleutian low, and the strong negative anomalous SLP presents over the maritime continent in the tropical region. This indicates that the strong SLP gradient between north and south is important for the wind variability over IDP [8]. This reveals that the two poles of the positive anomalous SLP over Siberia and the eastern North Pacific Ocean play an important role in driving the winds from mid-latitude, passing through the lower anomalous SLP area in the west Pacific Ocean to the IDP region. In 
addition, the strong negative anomalous SLP associated with the cyclonic circulation over the maritime continent plays a role in inducing the winds from the mid-latitude and winds over the equatorial area that result in the strengthening of the northeasterly wind over the IDP. It is noteworthy that the anomalous SLP over the eastern North Pacific Ocean is not significant, and the factor related to the evidence of the non-significant area will be pointed out later. These results reveal the linkage of the northeasterly wind governing a small area, such as the IDP, to the large-scale circulation, which agrees with the EAWM characteristic [3,5]. To give more explanation showing some relationship between the northeasterly low-level wind governing over the IDP and the EAWM, we will show evidence in a further analysis examining the relationship with the EAWM.

Figure 3. Spatial patterns of composite differences between strong and weak phases of (a) PCpri and (b) PC1sec. The vector and contour line are the differences of wind (meters per second) and sea level pressure (hectopascals), respectively, and the shading contour is the 0.05 significance level.
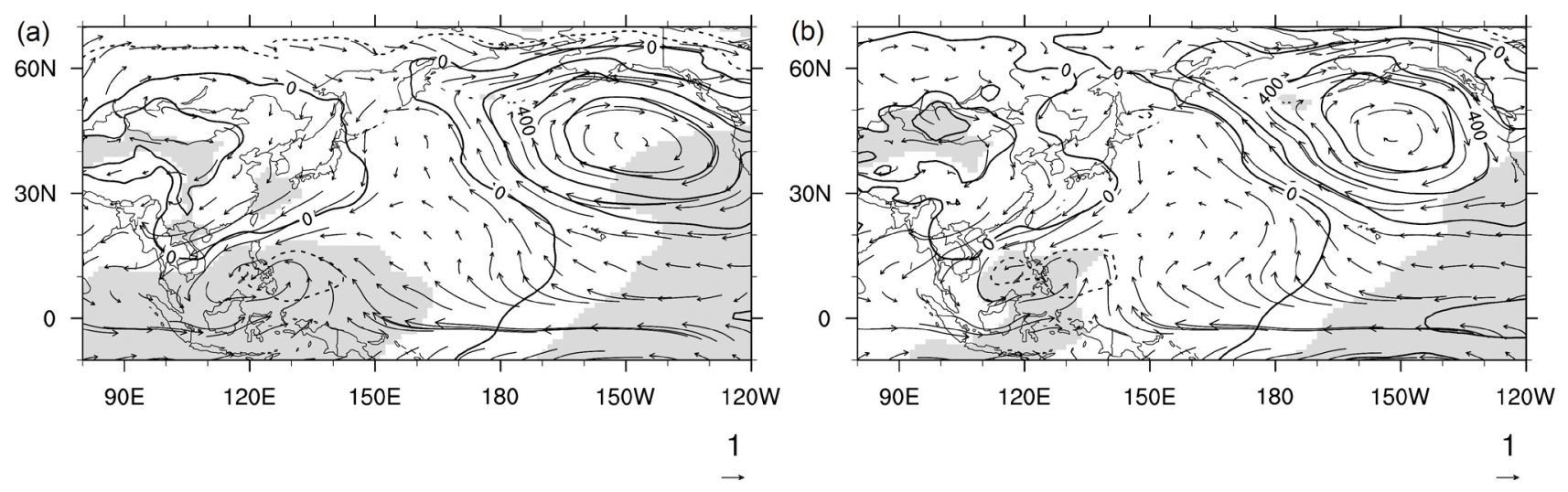

\subsection{The Relation of Wintertime Low-Level Wind Variability over the IDP to EAWM Indices}

Basically, the EAWM has been quantitatively characterized by changes in wind circulation and the SLP gradient. To measure its intensity and the variability of the EAWM, therefore, indices derived based on many aspects of these atmospheric variables were introduced. The indices can be divided into four different categories [12]. The first category is the EAWM intensity represented by low-level wind that flows along the East Asia coasts. It does not influence only East Asia, but it also affects the tropical region. The indices of this category are the best among other categories that show a good correlation with ENSO [12]. The second category is the indices derived from the pressure gradient that resulted from the difference between SH and Aleutian low (AL) influences [12]. The relation between the first and the second category indices are highly correlated, in particular the correlation between indices derived from wind at $10 \mathrm{~m}$ and SLP [34]. The third category is the indices related to upper level wind over East Asia, which captures the upper tropospheric East Asian jet stream. The last group of indices related to the East Asian trough shows high correlation with the index derived from the upper level wind [34] and is well correlated to the Arctic Oscillation (AO) [12] that influences the trough at $500 \mathrm{hPa}$ rather than that of $\mathrm{SH}[30]$.

Since the IDP is located in the tropics and far from the Arctic region, the indices derived from low-level winds, SLP and upper-level winds were selected. Although the PC1s were derived from the low-level 
wind analysis, the upper-level wind index was selected, because there are vertical circulation cells in which the low-level winds link to the upper-level winds. Those indices are the low-level wind indices, $I_{\mathrm{Ji}}, I_{\mathrm{Lu}}, I_{\mathrm{Chen}}$, and $I_{\mathrm{Liu}-\mathrm{L}}$ and $I_{\mathrm{Liu}-\mathrm{M}}$, introduced in previous studies [5,6,9,10], respectively. Next are the indices derived from SLP, named $I_{\mathrm{Xu}}[29]$ and $I_{\mathrm{Wu}}$ [30], respectively, and finally, the index derived from the upper level wind is named as $I_{\mathrm{Jhun}}$ [31]. These were used to investigate the connection between wintertime low-level wind over IDP and the EAWM.

The indices were calculated for the study period following the original procedures using the JRA-25 dataset. The correlation coefficients between PC1s and the EAWM indices are shown in Table 2. Note that the indices derived from meridional wind are presented in the opposite sign of the original indices, because the negative values denote the meridional wind blowing southward, which is consistent with the spatial patterns of wintertime low-level wind over the IDP. The correlations of PC1s to the EAWM indices are mostly statistically significant at the $95 \%$ confidence level.

Table 2. Correlation coefficients between PC1s and EAWM indices and ancillary information.

\begin{tabular}{cccc}
\hline Index & PC1pri & PC1sec & Parameter \\
\hline$I_{\text {Chen }}{ }^{*}$ & $0.56^{a}$ & $0.60^{a}$ & $v(10 \mathrm{~m})$ \\
$I_{\text {Liu-M }}{ }^{*}$ & 0.33 & 0.35 & $v(1,000 \mathrm{hPa})$ \\
$I_{\mathrm{Liu}-\mathrm{L}}{ }^{*}$ & $0.54^{a}$ & $0.59^{a}$ & $v(1,000 \mathrm{hPa})$ \\
$I_{\mathrm{Ji}}{ }^{*}$ & $0.58^{a}$ & $0.59^{a}$ & $v(1,000 \mathrm{hPa})$ \\
$I_{\mathrm{Lu}}{ }^{*}$ & $0.76^{a}$ & $0.72^{a}$ & $v(1,000 \mathrm{hPa})$ \\
$I_{\mathrm{Xu}}$ & $0.46^{b}$ & $0.44^{b}$ & $\mathrm{SLP}$ \\
$I_{\mathrm{Wu}}$ & $0.30^{b}$ & $0.31^{b}$ & $\mathrm{SLP}$ \\
$I_{\mathrm{Jhun}}$ & 0.34 & $0.38^{b}$ & $u(300 \mathrm{hPa})$ \\
\hline
\end{tabular}

Note: $a$ and $b$ denote significance levels at 0.01 and 0.05 , respectively; $u$ and $v$ denote zonal and meridional winds, respectively; * the index values were multiplied by -1 to keep the meaning of the meridional wind moving southward.

Further examination reveals that the indices derived from meridional winds mostly show a stronger association than do others. It is suggested that the northeasterly wind (as shown in Figure 2) influences the wintertime wind variability of the IDP and has a connection with the EAWM. The index concerning the mid-high latitude $\left(I_{\text {Liu-M }}\right)$ has less correlation with PC1s than the indices concerning low latitude areas $\left(I_{\mathrm{Chen}}, I_{\mathrm{Liu}-\mathrm{L}}, I_{\mathrm{Lu}}\right.$, and $\left.I_{\mathrm{Ji}}\right)$. This agrees with the different features of EAWM between mid-high and low latitudes [35], because anomalous northeasterly wind is significantly reflected by the index derived from low latitude wind $\left(I_{\text {Liu-L }}\right)$, rather than the index derived from mid-high latitude wind [10]. For the upper wind, some correlations with the $I_{\text {Jhun }}$ index have been shown. However, the correlation coefficient is not strong, compared to low-level wind at low latitude, and it is in a range between the $I_{\mathrm{Xu}}$ and $I_{\mathrm{Wu}}$ correlations that were derived by the SLP gradient over the mid-latitude. The reason for this is that the $I_{\mathrm{Jhun}}$ had a good relationship with the SH and AL [31].

Among correlations of PC1s with the indices, it was found that the correlation coefficient of PC1s to the $I_{\mathrm{Lu}}$ index is highest. Therefore, the $I_{\mathrm{Lu}}$ index is the best index to explain the wintertime wind variability over the IDP. Nevertheless, PC1 sec shows a little higher significant correlation to EAWM indices than that of PC1pri (Table 2). To represent a connection of wintertime northeasterly wind over 
the IDP to EAWM, PC1sec is a little better than PC1pri and has a better connection to EAWM over the low-latitude, rather than the mid-high latitude.

Figure 4. Spatial patterns of composite differences between positive and negative phases of the (a) $I_{\mathrm{Chen}},(\mathbf{b}) I_{\mathrm{Liu}-\mathrm{M}},(\mathbf{c}) I_{\mathrm{Liu}-\mathrm{L}},(\mathbf{d}) I_{\mathrm{Ji}},(\mathbf{e}) I_{\mathrm{Lu}},(\mathbf{f}) I_{\mathrm{Xu}},(\mathbf{g}) I_{\mathrm{Wu}}$ and $(\mathbf{h}) I_{\mathrm{Jhun}}$ indices. The vector and contour line are the differences of wind (meters per second) and sea level pressure (hectopascals), respectively, and the shading contour is the 0.05 significance level.
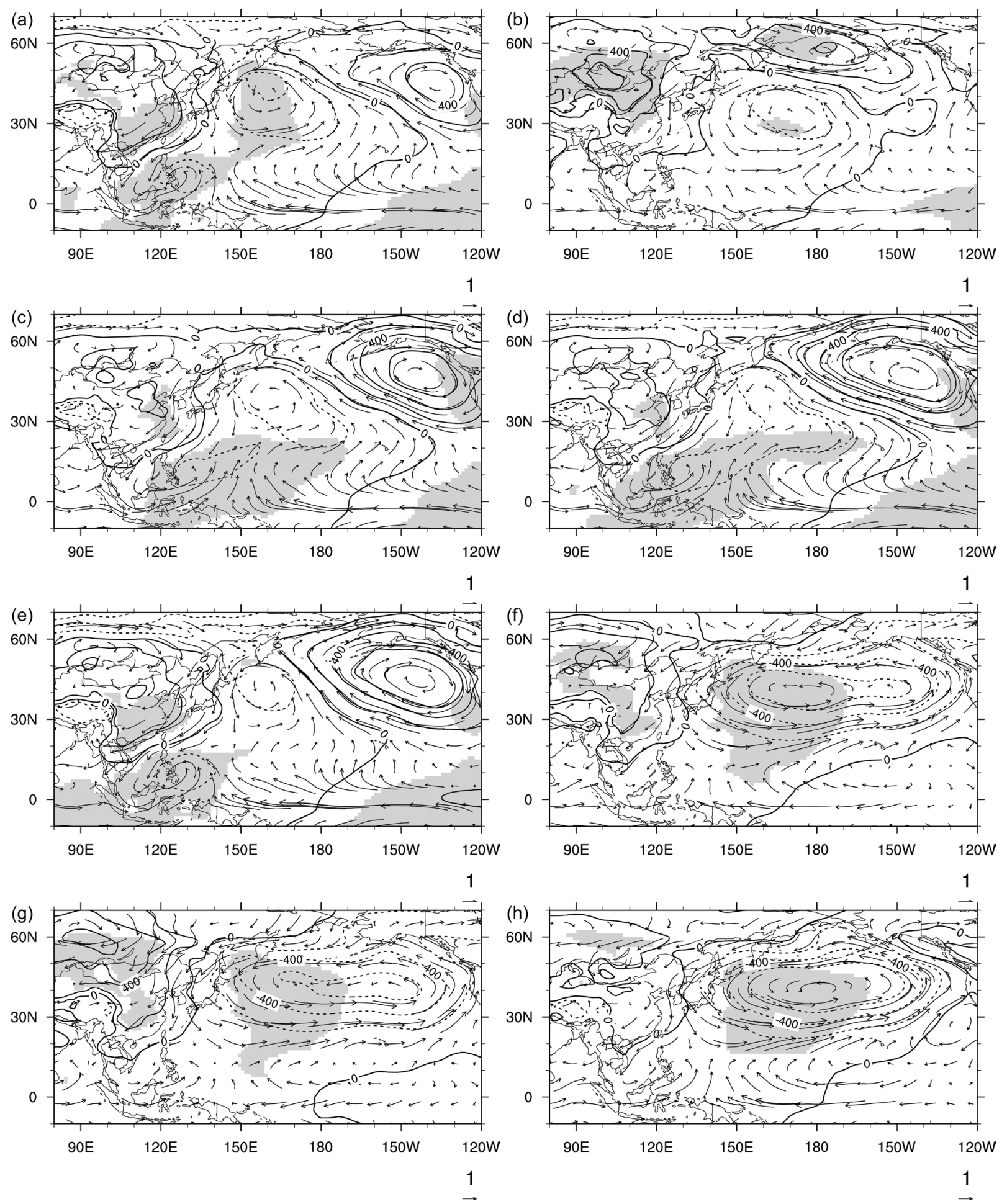
According to the difference in EAWM index definitions, the spatial patterns of each EAWM index are shown in Figure 4. The spatial patterns of the EAWM indices were derived from low-level wind, except $I_{\text {Liu-M }}$ (Figure 4a,c-e), presenting the features of strong EAWM, which are high pressure in the East Asian continent and low pressure in the adjacent ocean and deep East Asian trough [5], whereas high pressure presents over the eastern North Pacific Ocean (not significant, as before). For the $I_{\text {Liu-M }}$ index, there is a change in the westward direction of the high anomalous pressure present over the eastern North Pacific Ocean.

Moreover, the patterns show the low anomalous SLP and cyclonic circulation over the maritime continent in the tropical area and the western North Pacific Ocean, which agree with the associated features of EAWM [5]. It should be noted that the low anomalous SLP and cyclonic circulation in the western North Pacific Ocean does not obviously present in the patterns given by the PC1s (Figure 3). These indicate that the low anomalous SLP and cyclonic circulation in the western North Pacific Ocean play more important roles in the EAWM variability than the northeasterly wind variability over the IDP.

On the other hand, the composite patterns of the $I_{\mathrm{Xu}}, I_{\mathrm{Wu}}$ and $I_{\mathrm{Jhun}}$ indices show the contrast of SLP between the mainland and ocean, which indicates the definition of EAWM based on the thermal gradient (Figure 4g,h). They also present the absence of the high anomalous SLP over the eastern North Pacific Ocean, and their correlation coefficient values are smaller than those of the low-level wind EAWM indices. These mean that the high anomalous SLP over the eastern North Pacific Ocean located in the mid latitude is essential to drive the northeasterly wind over the IDP. Moreover, all patterns (Figures 3 and 4) show the high anomalous SLP over the mainland, which indicates the SH forcing is the major active climate feature influencing the EAWM [30] and the northeasterly wind over the IDP.

Nevertheless, the correlation analyses show that there is less influence of thermal contrast forcing between land and ocean than the influence of the western North Pacific low and the eastern North Pacific high, which affects the variability of northeasterly wind over the IDP. We separate the northeasterly wind variability over the IDP into two parts, using the regression technique that was used to separate the signal into the related part and the unrelated part with respect to the feature of interest [26]. The thermal contrast between the mainland and the ocean in the mid-latitude represented by the $I_{\mathrm{Xu}}$ index was considered as the feature of interest of the EAWM. The related parts of PC1s with respect to the $I_{\mathrm{Xu}}$ index were calculated by a linear regression of the PC1s; hereafter, both the $I_{\mathrm{Xu}}$-related parts of the $\mathrm{PC} 1 \mathrm{~s}$ are referred to as $\mathrm{PC} 1$ pri- $I_{\mathrm{Xu}}$ and $\mathrm{PC} 1 \mathrm{sec}-I_{\mathrm{Xu}}$. The $I_{\mathrm{Xu}}$-unrelated parts (PC1pri-res and $\mathrm{PC} 1$ sec-res) were computed as the difference between the PC index and the $I_{\mathrm{Xu}}$-related part.

The PC1pri- $I_{\mathrm{Xu}}$ and PC1pri-res explain $21 \%$ and $79 \%$ of the total variance, and the PC1sec- $I_{\mathrm{Xu}}$ and PC1sec-res explain $19 \%$ and $81 \%$, respectively. These suggest that the variability of the northeasterly wind over the IDP is less influenced by the thermal contrast forcing between the mainland and the North Pacific Ocean than the forcing of the unrelated part. The composite difference patterns of PC1s- $I_{\mathrm{Xu}}$ (Figure 5a,c) show the difference of pressure between the mainland and the North Pacific Ocean. These results show anomalous SLP and the cyclonic circulation over western North Pacific Ocean, which indicates the strong (weak) PC1s- $I_{\mathrm{Xu}}$ associated with cyclonic (anti-cyclonic) circulation over the western North Pacific Ocean. This agrees with the weak EAWM, which tends to induce the anomalous western North Pacific anticyclone, and vice versa for the strong EAWM [26]. The patterns of PC1s- $I_{\mathrm{Xu}}$ also present a branch of wind splitting at the south of Japan blowing along the coastline, which strengthens the northeasterly wind over the IDP. On the other hand, the patterns of PC1s-res 
(Figure 5b,d) present strong anomalous high pressure over the eastern North Pacific Ocean and Siberia and anomalous low pressure over the maritime continent, which agrees with the features of northeasterly wind variability over the IDP (Figure 3). The unrelated patterns present a branch of the EAWM blowing along the coastline, which are caused by the anomalous high pressures over Siberia and the eastern North Pacific Ocean, driving winds to the anomalous low pressure over the maritime continent. The $I_{\mathrm{Xu}}$-unrelated parts of the PC1pri (Figure $5 \mathrm{~b}$ ) shows the significant anomalous SLP over the eastern North Pacific Ocean acting as forcing, driving the wind in the zonal direction, whereas the $I_{\mathrm{Xu}}$-unrelated parts of the PC1 $1 \mathrm{sec}$ shows the significant anomalous SLP over the maritime continent as a forcing to induce the wind from mid-latitude to the IDP. It was noted that the significant anomalous SLP over the eastern North Pacific Ocean is absent in Figure 3. From these (Figure 5), the cause is the influence of the thermal contrast between the mainland and the ocean, defined by $I_{\mathrm{Xu}}$.

Figure 5. Spatial patterns of composite differences between positive and negative phases of (a) the $I_{\mathrm{Xu}}$-related part and (b) the $I_{\mathrm{Xu}}$-unrelated to PC1pri; (c) and (d) are the same as (a) and (b), but for the PC1sec. The vector and contour line are the differences of wind (meters per second) and sea level pressure (hectopascals), respectively, and the shading contour is the 0.05 significance level.
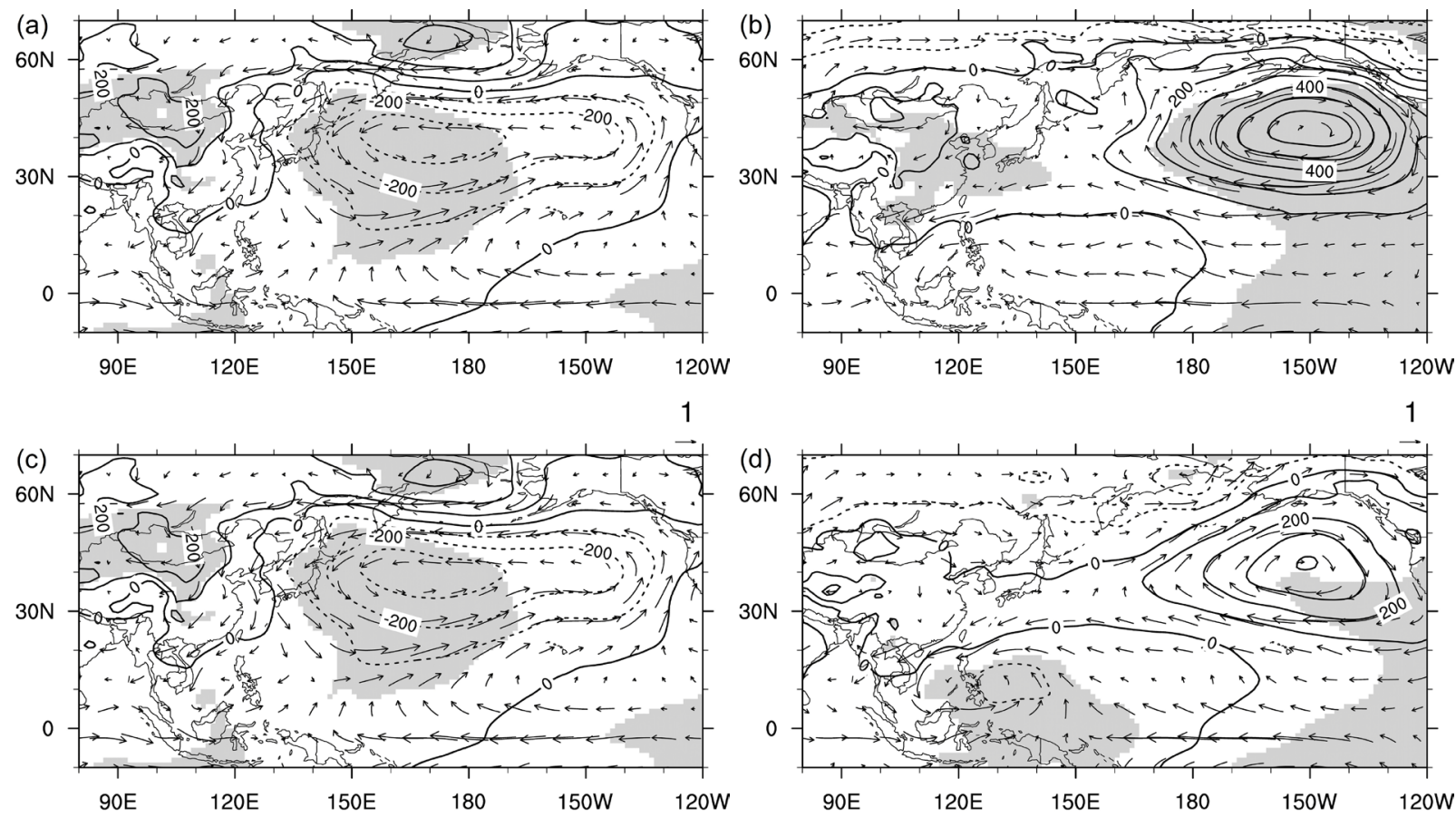

1

The northeasterly wind that is connected to a branch of the EAWM is influenced by the SLP forcing over the mainland, the eastern North Pacific Ocean and the maritime continent, but the anomalous low SLP and cyclonic circulation over the western North Pacific Ocean do not play a more important role in the northeasterly wind over the IDP. The results reveal the connection of the northeasterly wind over the IDP to the EAWM via a branch of the EAWM that blows along the coast of China and the influences of large-scale forcing that affect the low-level wind variability over the smaller region, which is the IDP. The EAWM variability indices defined by the thermal contrast between the East Asian and the adjacent ocean do not describe the variability over the IDP well. 


\section{The PC1s-SST Relationship}

A possible cause of a higher correlation between PC1s and low latitude EAWM wind indices rather than the others of mid-high latitudes, is the modulation with other active climate features, such as ENSO. This plays a role in the maritime continent during the winter monsoon [36]. The ENSO is an important phenomena revealed by SST variability in the equatorial Pacific Ocean. Many studies indicate that there is an association between EAWM and ENSO [3,17-19]. In addition, there is a significant correlation of the northeasterly wind over the IDP represented by PC1s (hereafter, referred to as the northeast (NE) monsoon) with the low latitude EAWM characteristic. It is a possibility that there is another possible climate forcing influencing the variability of wintertime low-level wind over the IDP. This would be the forcing from SST variability in the Pacific Ocean and is interesting for revealing the relationship between NE monsoon and SST in the Pacific Ocean, which has not been completely investigated. The PC1s were employed to construct the correlation maps of these to sea surface temperature anomalies (SSTAs) for investigation, as shown in Figure 6.

Figure 6. Correlation maps between (a) the primary part of the leading principal component (PC1pri) to sea surface temperature anomalies; (b) is the same as (a), but for the secondary component $(\mathrm{PC} 1 \mathrm{sec})$. Shading presents correlation coefficients, and the thick and thin contour lines denote the significance levels at 0.01 and 0.05 , respectively. SSTA, sea surface temperature anomaly.
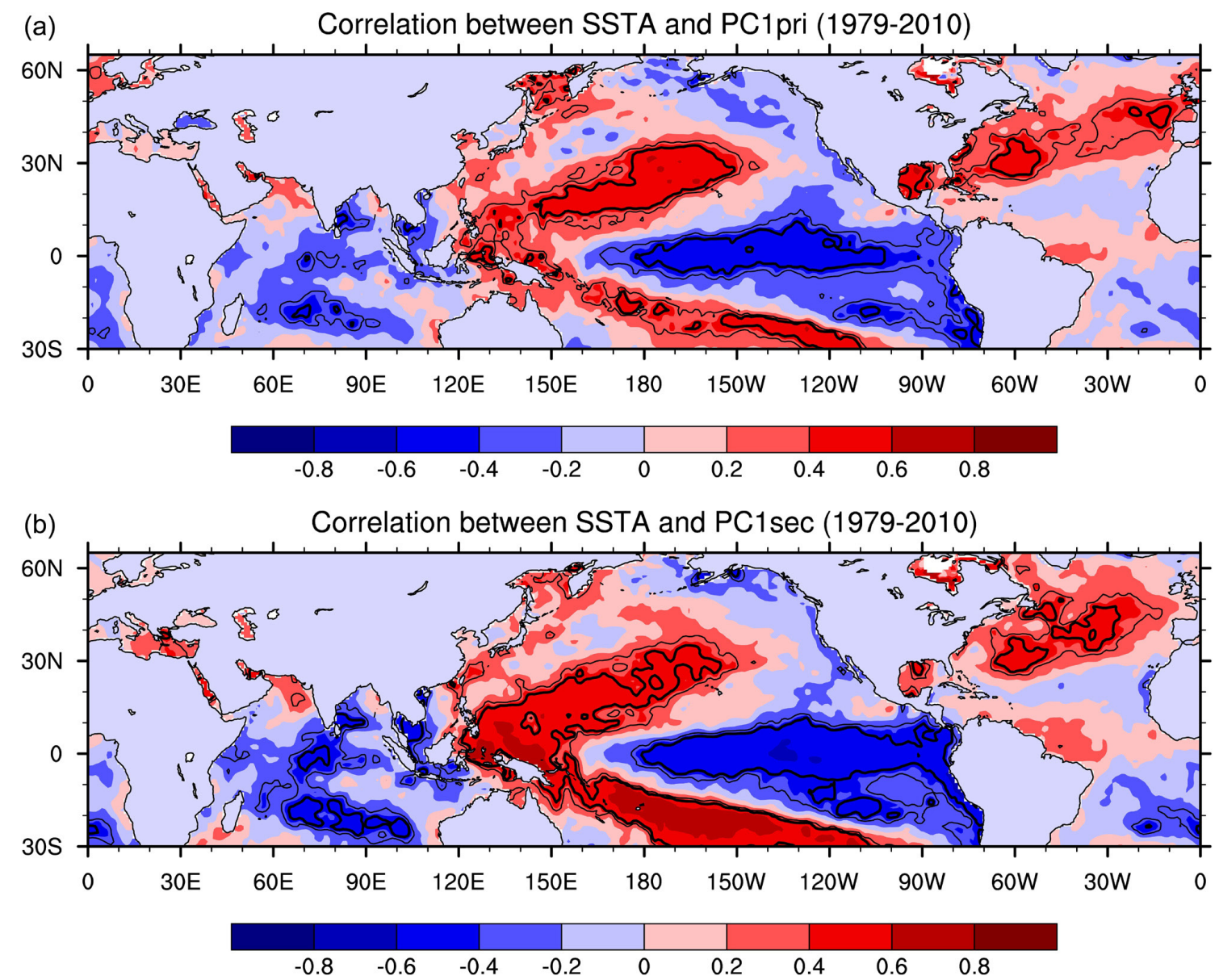
The figure shows a negative correlation between PC1s and SSTA in the Indian Ocean, with smaller magnitudes than those in the Pacific Ocean, while the significantly correlated areas in the Pacific Ocean are wider than those in the Indian Ocean. Based on this evidence, it is possible that the SST variability in the Pacific Ocean plays a greater role in the wintertime low-level wind variability over the IDP than that of the Indian Ocean.

Over the tropical central-east Pacific Ocean, there are negative correlations between PC1s and SSTAs. Increasing PC1s values correlated with decreasing SSTAs. This indicates that the cooling (warming) of SST over the tropical central-east Pacific Ocean is relatively in phase with the strengthening (weakening) of northeasterly winds over the IDP. For the west Pacific Ocean, this shows a positive correlation, which differs from the correlation presenting for the tropical central-east Pacific Ocean. The positive correlation shows a V-shape in the horizontal plane pattern, which extends eastward and poleward, indicating that an increase in PC1 values is correlated with high SSTA. This implies that the warming (cooling) of SST over the tropical central-east Pacific Ocean is related to the strengthening (weakening) of northeasterly wind over the IDP. These results are quite consistent with studies [5,20] and agrees with a previous study [7] that suggests the warm SSTA in the tropical central-eastern Pacific Ocean leading to the weakening of the western Pacific Hadley cell, causing the EAWM to be weakened. On the other hand, the cold SSTA in the central-eastern Pacific Ocean leads to presenting a strong EAWM, with air ascending in the equatorial western Pacific Ocean, resulting from the ENSO [7].

To confirm the association between PC1s and SSTA in the equatorial Pacific Ocean, the correlation analysis for -11 - to +11-month lags was performed. An important activity in the Pacific Ocean, El Niño, has been measured and monitored through SSTA variation [37]. The Niño3.4 index, which is averaged SSTA over $5^{\circ} \mathrm{S}-5^{\circ} \mathrm{N}, 170^{\circ}-120^{\circ} \mathrm{W}$, was used for the analysis. For the importance of the Indian Ocean, the influence of SST anomalies in the tropical Indian Ocean (TIO) is measured by the index (hereafter, referred to as the TIO index) introduced by [8], which is determined by the average of SSTAs over the TIO area $\left(40^{\circ}-90^{\circ} \mathrm{E}, 10^{\circ} \mathrm{S}-10^{\circ} \mathrm{N}\right)$. It was used to confirm the association between PC1s and SSTAs in the Indian Ocean. Three-month running means were performed on SSTA to reduce the influence of seasonal means before the analysis, as suggested by a previous study [38]. The result is shown in Figure 7.

The result shows significant negative correlations of PC1s to Niño3.4 index on previous months and following months, which starts from three months for PC1pri (Figure 7a) and five months for PC1sec (Figure 7b) before DJF (0), and both persist for three months later. Thus, the air-sea interaction over the equatorial Pacific Ocean affects the variability of NE monsoon over the IDP represented by $\mathrm{PC} 1 \mathrm{~s}$. This result indicates that there is an association between NE monsoon variability and ENSO. The ENSO can trigger the monsoon over the IDP, and its relation persists a few months after the winter. The negative correlations between PC1s and the Niño3.4 index imply that the strengthened NE monsoon is associated with the negative phase of Niño3.4, which is considered as La Niña when the Niño3.4 values exceed $-0.5{ }^{\circ} \mathrm{C}$, consecutively, and vice versa for the weakened NE monsoon associated with El Niño.

For the TIO, there is a significant correlation between PC1pri and the TIO index before winter from January to June, but the PC1sec significant correlation is absent, as shown in Figure 7c,d. The result implies that the variability of SSTA in the TIO correlated to the variation of the NE monsoon over the 
IDP, due to the wind in the parallel direction to the eigenvector field of the leading mode, rather than that in the perpendicular direction. The relation of PC1s to the TIO index also shows early and less significant influence on the wintertime low-level winds over the IDP, as compared to the SSTA variation in the tropical Pacific Ocean. This agrees with a previous study, that suggested the SST anomalies in TIO are likely to be the factor driving the EAWM [8], but our result shows little difference in the time period, showing early significant correlation. Although this is different, it is interesting to study further, including the direct and indirect influences or the modulation of SST anomalies in TIO with ENSO. For the next analysis, we only focus on ENSO during the boreal winter.

Figure 7. Correlation between (a) the primary part of the leading principal component and Niño3.4 represented by the three-month running means of SSTA ( 0 represents the corresponding DJF mean of SSTA variation, and the negative and positive running means represent the previous and following months considered at the middle point, respectively); and (b) is the same as (a) but for the secondary component. (c) and (d) are similar to (a) and (b), but for the tropical Indian Ocean (TIO) index. The shading presents statistical significance at the $95 \%$ confidence level.

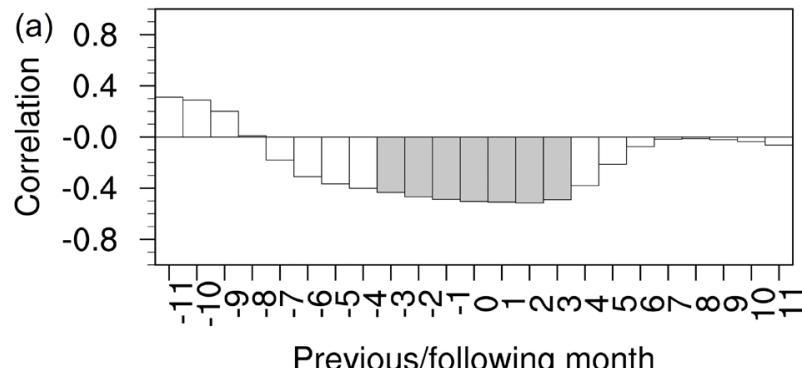

Previous/following month

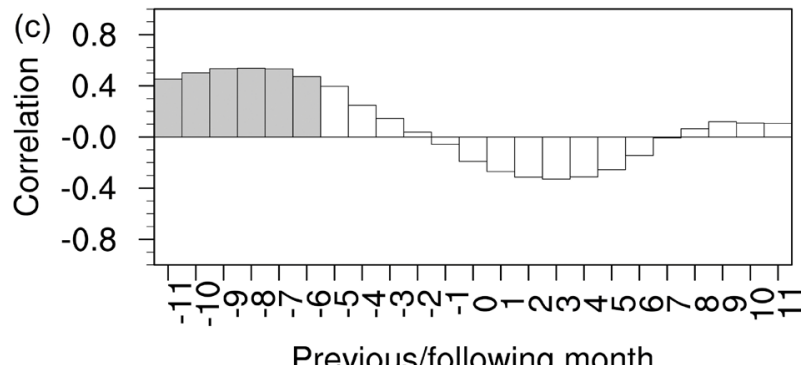

Previous/following month

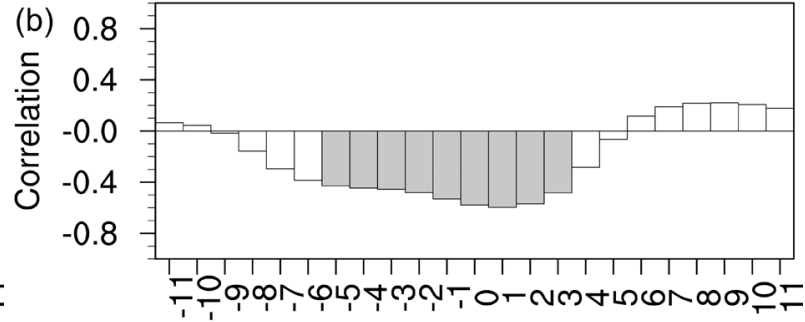

Previous/following month

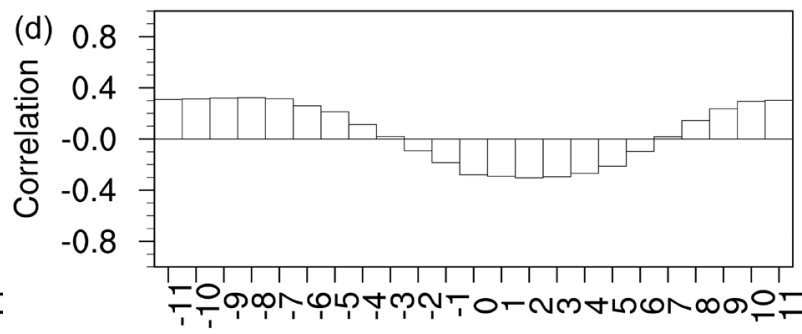

Previous/following month

To investigate the mechanism related to the influence of ENSO, regression analysis was applied [26]. The PC1s-res, which represent the variability of northeasterly wind over the IDP without the influence of the thermal contrast in the temperate region, were analyzed to separate them into the ENSO-related part (PC1s-res-EN) and the ENSO-unrelated part (PC1s-res-uEN) by the regression technique, as described in a previous study [26]. The contributions of ENSO to PC1pri-res and PC1sec-res are $17 \%$ and $25 \%$ of their total variances, respectively, whereas the contributions of the ENSO unrelated part are $83 \%$ and $75 \%$ for PC1pri-res and PC1sec-res, respectively. The ENSO-related patterns show the positive anomalous SLP over the temperate mainland and the north Eastern Pacific Ocean (Figure 8a,c). They also present the anomalous low pressure in the west Pacific Ocean with the cyclonic circulation around the maritime continent. These indicate that the variability of northeasterly wind over the IDP is influenced by wind blowing from the mid-latitude to the IDP, which is induced by the cyclonic 
circulation. These reveal the role of ENSO. On the other hand, the ENSO-unrelated part of PC1pri-res (Figure 8b) presents wider positive anomalous SLP over the eastern Pacific Ocean, which implies the high pressure over this area influencing the wind variability over the IDP in a parallel direction to the directions of wind vectors given by the eigenvector. For the PC1sec-res, which is related to the variation of winds in the perpendicular direction, the pattern (Figure 8d) shows two poles of the positive anomalous SLP over the areas around Siberia and the Gulf of Alaska without the obvious SLP forcing in the tropical area. These indicate that the two poles in the mid-latitude influence the variability of northeasterly wind over the IDP without the ENSO forcing by driving winds in the high latitude to the tropical region. Therefore, the variability of northeasterly wind over the IDP is influenced by the modulation of the tropical and temperate forcing, which are the ENSO and the SLP forcing in the mid-latitude.

Figure 8. Spatial patterns of composite differences between positive and negative phases of (a) the El Niño-Southern Oscillation (ENSO) related part and (b) the unrelated part of PC1pri-res; (c) and (d) are the same as (a) and (b), but for PC1sec-res. The vector and contour line are the differences of wind (meters per second) and sea level pressure (hectopascals), respectively, and the shading contour is the 0.05 significance level.
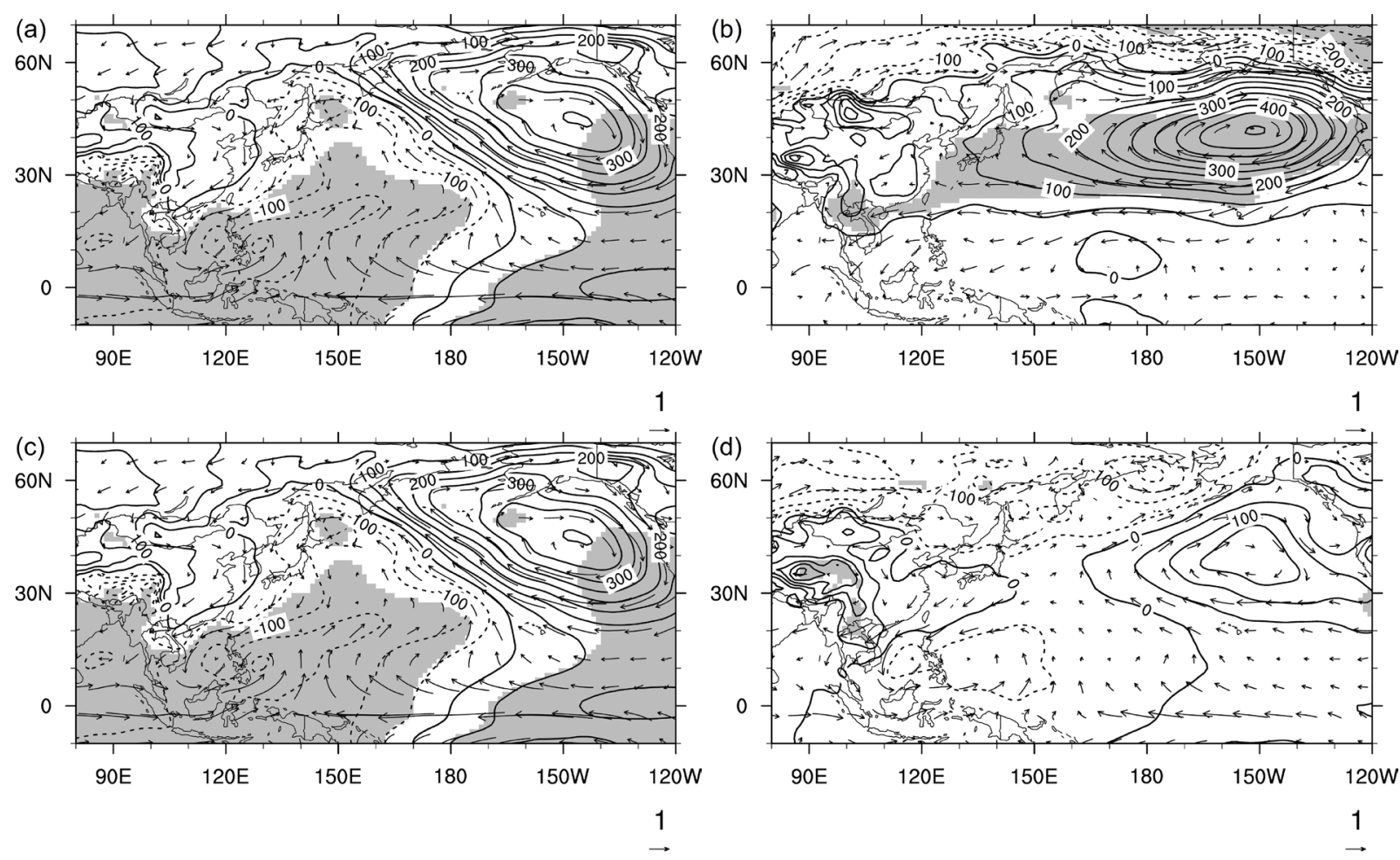

Nevertheless, a previous study [39] reports that the relationship between the ENSO and the EAWM is not stationary, and the ENSO exerts influence on the EAWM through the Pacific-East Asian teleconnection (an anomalous anticyclonic circulation around the western North Pacific to the east of The Philippines). The influence of ENSO on EAWM has been weak since 1976 [39], but we observed the association with ENSO. This can be explained by the meridional winds, which are always significant, and the winds associated with the anticyclone (see Figure 3 in [39]). Hence, the non-stationary ENSO-EAWM relationship does not influence the IDP region. 
For the next analysis, it is important to present evidence of the NE monsoon impact on precipitation, because there is the association between PC1s and ENSO, the linkages between rainfall and ENSO [36,40-42] and the linkage between ENSO with EAWM [7]. The monthly gridded dataset of precipitation from the University of Delaware (UDel) [28] from the National Oceanic and Atmospheric Administration/Office of Oceanic and Atmospheric Research/Earth System Research Laboratory (NOAA/OAR/ESRL) was used for the analysis.

The spatial distribution of climatic precipitation covering a period 1979-2010 during the boreal winter shows more precipitation on the southern part of IDP, along the coastline area of Vietnam, and some parts of Guangxi and Guangdong of China, than the mainland of IDP, which includes Myanmar, the upper part of Thailand, Laos and Cambodia, except some parts of Arunachal Pradesh of Northeast India and the northern part of Myanmar (Figure 9a). The possible impact of the NE monsoon on precipitation over the IDP is revealed by regression analysis of precipitation on PC1s.

Figure 9. Spatial distributions of (a) climatic mean during the boreal winter of monthly total precipitation from 1979 to 2010, (b) the regressed precipitation anomaly on PC1pri, and (c) is the same as (b), but for the PC1sec. The shading color shows the regression results in units of centimeters per month, whereas the dashed line presents the significance level at 0.05 .
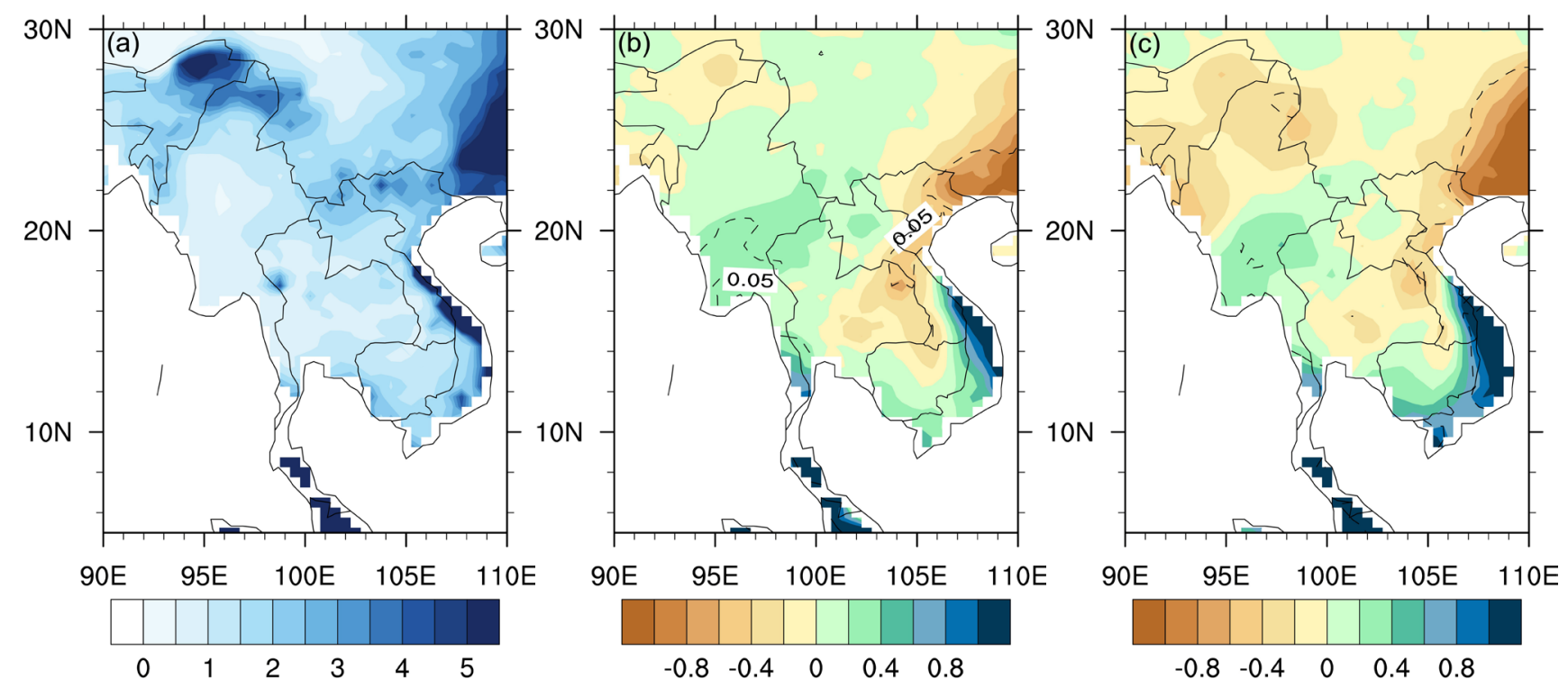

The regressed precipitation patterns (Figure 9b,c) are positive over the area from the south central coast of Vietnam to the Mekong Delta, the southern part of Cambodia and the southern tip of IDP, which indicate the enhancement of northeasterly wind strength (the increasing of PC1s values), resulting in more precipitation over these areas, and vice versa for the weakening of the NE monsoon (the decreasing of PC1s values), showing the reduction of precipitation there in terms of a linear relationship. These results agree with the blowing pathway of the wind connected with the EAWM. It passes the South China Sea, penetrating into the IDP, which carries moisture from the SCS and the Gulf of Thailand to the eastern coast area and the southern area of the IDP, respectively. On the other hand, the negative presence over areas around Guangxi and Guangdong of China and the northern part of Vietnam, significantly, indicates the positive phase of the northeasterly wind, resulting in wind 
blowing more southward, carrying a dry air mass, causing less precipitation over these areas (Figure 9b,c). According to a previous study [20], these results (Figures 6 and 9) are like those reported in [20], which indicate that the impact on precipitation over the IDP was influenced by the conventional ENSO. Therefore, there is a possibility to indicate possible impacts on precipitation in the IDP by the PC1 indices, utilizing the relationship among the PC1, EAWM and ENSO indices.

\section{Conclusions}

Over the IDP, we revealed spatio-temporal wintertime wind variability and have identified the principal mode of the wind at $850 \mathrm{hPa}$ by using the EOF analysis for complex numbers. The spatial patterns given by the regression of wind on the leading PC and the patterns given by the composite analysis show prominent northeasterly wind over the IDP, known as the NE monsoon, which agree with the characteristic of the EAWM and its influence on the tropical region. Namely, these results are consistent with the circulation characteristic of EAWM, exhibiting wind blowing along the coast of East Asia and the influence of the Borneo vortex. Thus, the first mode of wintertime wind variability over the IDP is affected by the EAWM via wind blowing that passes through the SCS to the IDP.

We further presented the possible connection of wintertime low-level wind variability over the IDP to the EAWM on the basis of the correlations between the PC1 and EAWM indices. The PC1 shows good correlations with the EAWM indices, characterized by lower latitude wind than others. The comparison of correlations between the PC1 and EAWM indices indicates that the $I_{\mathrm{Lu}}$ index is a suitable EAWM index to reveal the variability of the winter monsoon over the IDP.

Hence, the relation of PC1s to EAWM indices is not fully correlated. The correlation analyses focusing on SSTA show that there is a more significant correlation between PC1s and SSTA in the Pacific Ocean than in the Indian Ocean, quite similar to the ENSO pattern. Thus, another possible forcing influencing the NE monsoon variability over the IDP is mainly related to SSTA in the Pacific Ocean. The ENSO represented by the Niño3.4 index was used to reveal its association with the NE monsoon variability over the IDP. The results show that the variability is influenced by wind blowing from the mid-latitude to the IDP, which is induced by the cyclonic circulation related to the ENSO-related part of PC1s. Although the relationship between the ENSO and the EAWM is not stationary, the meridional wind is important [39]. Therefore, the non-stationary ENSO-EAWM relationship does not influence the IDP region, and the wintertime low-level wind variability over the IDP is influenced by the modulation of the tropical and temperate forcing.

Furthermore, the result of the analysis showed the strengthening (weakening) of the NE monsoon, causing more (less) precipitation over the central coast of Vietnam to the Mekong Delta, the southern part of Cambodia and the southern tip of the IDP. It is an interesting challenge to understand more about the winter monsoon over the IDP associated with ENSO by a modeling study and utilizing the Niño3.4 index to develop a forecast system of monsoons and their impacts. Furthermore, it is required to obtain a better understanding, particularly in terms of the non-linear relationship between another forcing, such as the Indian Ocean Dipole, and the winter monsoon over the IDP. 


\section{Acknowledgments}

The authors are grateful to three anonymous reviewers and the editor. We wish to acknowledge the Japan Meteorological Agency and the Central Research Institute of Electric Power Industry for the JRA-25 data and the Met Office Hadley Centre for Climate Change for the HadISST data. We also thank the Joint Graduate School of Energy and Environment, King Mongkut's University of Technology Thonburi (KMUTT), and the Center for Energy Technology and Environment, the Ministry of Education, Thailand, for financial and study support. This extends to the Department of Mathematics, KMUTT and the Thailand Research Fund. This study was supported by the research grant of the National Research Council of Thailand.

\section{Author Contributions}

The authors identified the framework of this study, and contributed extensively to this paper. Sirapong Sooktawee prepared the manuscript, and developed the computational codes for all analyses. Usa Humphries, Atsamon Limsakul, and Prungchan Wongwises gave the meaningful suggestions including mathematical perspective. All authors discussed the results of this manuscript throughout all processes.

\section{Conflicts of Interest}

The authors declare no conflict of interest.

\section{References}

1. Wang, B.; Clemens, S.C.; Liu, P. Contrasting the Indian and East Asian monsoons: Implications on geologic timescales. Mar. Geol. 2003, 201, 5-21.

2. He, J.; Ju, J.; Wen, Z.; LÜ, J.; Jin, Q. A review of recent advances in research on Asian monsoon in China. Adv. Atmos. Sci. 2007, 24, 972-992.

3. Huang, R.; Chen, J.; Wang, L.; Lin, Z. Characteristics, processes, and causes of the spatio-temporal variabilities of the East Asian monsoon system. Adv. Atmos. Sci. 2012, 29, 910-942.

4. Wangwongchai, A.; Sixiong, Z.; Qingcun, Z. A case study on a strong tropical disturbance and record heavy rainfall in Hat Yai, Thailand during the winter monsoon. Adv. Atmos. Sci. 2005, 22, 436-450.

5. Chen, W.; Graf, H.; Huang, R. The interannual variability of East Asian Winter Monsoon and its relation to the summer monsoon. Adv. Atmos. Sci. 2000, 17, 48-60.

6. Ji, L.; Shuqing, S.; Arpe, K.; Bengtsson, L. Model study on the interannual variability of Asian winter monsoon and its influence. Adv. Atmos. Sci. 1997, 14, 1-22.

7. Zeng, G.; Wang, W.-C.; Sun, Z.; Li, Z. Atmospheric circulation cells associated with anomalous East Asian winter monsoon. Adv. Atmos. Sci. 2011, 28, 913-926.

8. Wang, L.; Chen, W. An intensity index for the East Asian winter monsoon. J. Clim. 2013, doi: 10.1175/JCLI-D-13-00086.1.

9. Lu, E.; Chan, J.C.L. A unified monsoon index for South China. J. Clim. 1999, 12, 2375-2385. 
10. Liu, G.; Ji, L.-R.; Shu-Qing, S.; Xin, Y.-F. Low- and mid-high latitude components of the East Asian winter monsoon and their reflecting variations in winter climate over eastern China. Atmos. Ocean. Sci. Lett. 2012, 5, 195-200.

11. Srikul, C.; Sukawat, D. An empirical orthogonal function (EOF) analysis of Southeast Asian summer monsoon decomposition. Far East J. Appl. Math. 2012, 68, 55-71.

12. Wang, L.; Chen, W. How well do existing indices measure the strength of the East Asian winter monsoon? Adv. Atmos. Sci. 2010, 27, 855-870.

13. Zhang, Y.; Li, T.; Wang, B.; Wu, G. Onset of the summer monsoon over the Indochina peninsula: Climatology and interannual variations. J. Clim. 2002, 15, 3206-3221.

14. Yokoi, S.; Satomura, T.; Matsumoto, J. Climatological characteristics of the intraseasonal variation of precipitation over the Indochina peninsula. J. Clim. 2007, 20, 5301-5315.

15. Takahashi, H.G.; Fujinami, H.; Yasunari, T.; Matsumoto, J. Diurnal rainfall pattern observed by Tropical Rainfall Measuring Mission Precipitation Radar (TRMM-PR) around the Indochina peninsula. J. Geophys. Res.: Atmos. 2010, doi: 10.1029/2009JD012155.

16. Takahashi, H.G.; Fukutomi, Y.; Matsumoto, J. The Impact of long-lasting northerly surges of the East Asian winter monsoon on tropical cyclogenesis and its seasonal march. J. Meteorol. Soc. Jpn. 2011, 89A, 181-200.

17. Zhang, Y.; Sperber, K.R.; Boyle, J.S. Climatology and interannual variation of the East Asian winter monsoon: Results from the 1979-95 NCEP/NCAR reanalysis. Mon. Wea. Rev. 1997, 125, 2605-2619.

18. Wang, B.; Wu, R.; Fu, X. Pacific-East Asian teleconnection: How does ENSO affect East Asian climate? J. Clim. 2000, 13, 1517-1536.

19. Zhou, W.; Wang, X.; Zhou, T.J.; Li, C.; Chan, J.C.L. Interdecadal variability of the relationship between the East Asian winter monsoon and ENSO. Meteorol. Atmos. Phys. 2007, 98, 283-293.

20. Feng, J.; Wang, L.; Chen, W.; Fong, S.K.; Leong, K.C. Different impacts of two types of Pacific Ocean warming on Southeast Asian rainfall during boreal winter. J. Geophys. Res.: Atmos. 2010, doi: 10.1029/2010JD014761.

21. Onogi, K.; Tsutsui, J.; Koide, H.; Sakamoto, M.; Kobayashi, S.; Hatsushika, H.; Matsumoto, T.; Yamazaki, N.; Kamahori, H.; Takahashi, K. et al. The JRA-25 reanalysis. J. Meteorol. Soc. Jpn. 2007, 85, 369-432.

22. Hardy, D.M.; Walton, J.J. Principal components analysis of vector wind measurements. J. Appl. Meteorol. 1978, 17, 1153-1162.

23. Legler, D.M. Empirical orthogonal function analysis of wind vectors over the tropical Pacific region. Bull. Am. Meteorol. Soc. 1983, 64, 234-241.

24. Zhao, X.; Hou, Y.; Qi, P. Interpretation of sea surface wind interannual vector EOFs over the China seas. Chin. J. Oceanol. Limnol. 2010, 28, 340-343.

25. Hannachi, A.; Jolliffe, I.T.; Stephenson, D.B. Empirical orthogonal functions and related techniques in atmospheric science: A review. Int. J. Climatol. 2007, 27, 1119-1152.

26. Chen, W.; Feng, J.; Wu, R. Roles of ENSO and PDO in the link of the East Asian winter monsoon to the following summer monsoon. J. Clim. 2013, 26, 622-635. 
27. Rayner, N.A.; Parker, D.E.; Horton, E.B.; Folland, C.K.; Alexander, L.V.; Rowell, D.P.; Kent, E.C.; Kaplan, A. Global analyses of sea surface temperature, sea ice, and night marine air temperature since the late nineteenth century. J. Geophys. Res.: Atmos. 2003, doi: 10.1029/2002JD002670.

28. Legates, D.R.; Willmott, C.J. Mean seasonal and spatial variability in gauge-corrected, global precipitation. Int. J. Climatol. 1990, 10, 111-127.

29. Xu, J.; Chan, J.C.L. The role of the Asian-Australian monsoon system in the onset time of El Niño events. J. Clim. 2001, 14, 418-433.

30. Wu, B.; Wang, J. Winter Arctic oscillation, Siberian high and East Asian winter monsoon. Geophys. Res. Lett. 2002, doi: 10.1029/2002GL015373.

31. Jhun, J.-G.; Lee, E.-J. A new East Asian winter monsoon index and associated characteristics of the winter monsoon. J. Clim. 2004, 17, 711-726.

32. Juneng, L.; Tangang, F.T.; Reason, C.J.C. Numerical case study of an extreme rainfall event during 9-11 December 2004 over the east coast of Peninsular Malaysia. Meteorol. Atmos. Phys. 2007, 98, 81-98.

33. Chang, C.P.; Harr, P.A.; Chen, H.J. Synoptic disturbances over the equatorial South China Sea and western maritime continent during boreal winter. Mon. Weather Rev. 2005, 133, 489-503.

34. Gao, H. Comparison of East Asian winter monsoon indices. Adv. Geosci. 2007, 10, 31-37.

35. Chen, Z.; Wu, R.; Chen, W. Distinguishing interannual variations of the northern and southern modes of the East Asian winter monsoon. J. Clim. 2013, doi: 10.1175/JCLI-D-13-00314.1.

36. Juneng, L.; Tangang, F. Evolution of ENSO-related rainfall anomalies in Southeast Asia region and its relationship with atmosphere-ocean variations in Indo-Pacific sector. Clim. Dyn. 2005, 25, 337-350.

37. Trenberth, K.E.; Stepaniak, D.P. Indices of El Niño evolution. J. Clim. 2001, 14, 1697-1701.

38. Wang, L.; Chen, W.; Zhou, W.; Huang, R. Interannual variations of East Asian trough axis at 500 $\mathrm{hPa}$ and its association with the East Asian winter monsoon pathway. J. Clim. 2009, 22, 600-614.

39. Wang, L.; Chen, W.; Huang, R. Interdecadal modulation of PDO on the impact of ENSO on the East Asian winter monsoon. Geophys. Res. Lett. 2008, doi: 10.1029/2008GL035287.

40. Limsakul, A.; Limjirakan, S.; Suttamanuswong, B. Asian summer monsoon and its associated rainfall variability in Thailand. Environ. Asia 2010, 3, 79-89.

41. Sen Roy, S.; Sen Roy, N. Influence of Pacific decadal oscillation and El Niño southern oscillation on the summer monsoon precipitation in Myanmar. Int. J. Climatol. 2011, 31, 14-21.

42. Yen, M.-C.; Chen, T.-C.; Hu, H.-L.; Tzeng, R.-Y.; Dinh, D.T.; Nguyen, T.T.T.; Wong, C.J. Interannual variation of the fall rainfall in central Vietnam. J. Meteorol. Soc. Jpn. 2011, 89A, 259-270.

(C) 2014 by the authors; licensee MDPI, Basel, Switzerland. This article is an open access article distributed under the terms and conditions of the Creative Commons Attribution license (http://creativecommons.org/licenses/by/3.0/). 